\title{
Effects of thoracic epidural anesthesia on hemodynamic changes during tracheal intubation
}

Department of Anesthesiology and Pain Medicine, Soonchunhyang University Bucheon Hospital, Bucheon, *Soonchunhyang University Gumi Hospital, Gumi, College of Medicine, Soonchunhyang University, Korea

Sun Young Park, M.D., Bon Sung Koo, M.D., Joon Ho Lee, M.D., Sung Hwan Cho, M.D., Sang Hyun Kim, M.D., Won Seok Chae, M.D., Ph.D., Dong Gi Lee, M.D., Ph.D.*, Hee Cheol Jin, M.D., Ph.D., Jeong Seok Lee, M.D., Ph.D., and Yong Ik Kim, M.D., Ph.D.

Background: We sought to assess whether increasing a single dose of $1.5 \%$ lidocaine during thoracic epidural anesthesia (TEA) could suppress hemodynamic responses after laryngoscopy and tracheal intubation.

Methods: A total of 81 patients (ASA physical status I and II, aged 45-75) who scheduled for major abdominal surgery were enrolled. Patients were randomly assigned to three groups, for epidural injection of different amounts of $1.5 \%$ lidocaine: $0.1 \mathrm{ml} / \mathrm{kg}(\mathrm{L} 0.1, \mathrm{n}=27), 0.2 \mathrm{ml} / \mathrm{kg}(\mathrm{L} 0.2, \mathrm{n}=27)$, and $0.3 \mathrm{ml} / \mathrm{kg}(\mathrm{L} 0.3, \mathrm{n}=27)$. After $15 \mathrm{~min}$, general anesthesia was induced with intravenous thiopental sodium $(5 \mathrm{mg} / \mathrm{kg})$ and rocuronium $(0.9 \mathrm{mg} / \mathrm{kg})$, followed by tracheal intubation. Changes in blood pressure and heart rate were recorded for $3 \mathrm{~min}$ after intubation. Maximum percentage increases in systolic blood pressure (SBP) during the $3 \mathrm{~min}$ after tracheal intubation from baseline and the induction value were compared.

Results: The maximum increases in SBP from baseline values were significantly higher in L0.1 than in L0.2 and L0.3 (22.6\%; 95\% CI, $12.2-33.0 \%$; $-0.5 \%$; 95\% CI, $-11.1-10.0 \%$; and $-6.9 \%$; 95\% CI, $-13.9-0.0 \%$, respectively), whereas the maximum increases from induction values did not differ significantly.

Conclusions: Preoperative TEA using a single dose of $1.5 \%$ lidocaine at $0.2 \mathrm{ml} / \mathrm{kg}$ attenuated hemodynamic responses during tracheal intubation but did not completely suppress blood pressure reactions to laryngoscopy and tracheal intubation. (Korean J Anesthesiol 2008; 55: 429 35)

Key Words: epidural lidocaine, hemodynamic response, thoracic epidural anesthesia, tracheal intubation.

\section{INTRODUCTION}

Thoracic epidural anesthesia (TEA), combined with general anesthesia, is widely used for its beneficial effects during the intra-and postoperative periods. ${ }^{1,2)}$ If preoperative TEA were to provide a sympathetic blockade sufficient to inhibit hemodynamic responses during tracheal intubation, its use may also be beneficial during the preoperative period.

Previous studies $^{3-5)}$ have demonstrated that preoperative TEA can inhibit, sometimes completely, the hemodynamic responses

Received : June 24, 2008

Corresponding to : Sang Hyun Kim, Department of Anesthesiology and Pain Medicine, Soonchunhyang University Bucheon Hospital, 1174, Jung 1-dong, Wonmi-gu, Bucheon 420-767 Korea. Tel: 82-32-6215328, Fax: 82-32-621-5322

E-mail: aurellius@naver.com during laryngoscopy and tracheal intubation. However, there are some concerns in using this method to attain a hemodynamic advantage. First, although there have been conflicting results as to whether epidural analgesia provides sympathetic blockade to about the same extent as sensory blockade, ${ }^{6,7)}$ it might be necessary to provide sensory analgesia covering the entire thoracolumbar sympathetic nervous system to suppress sympathetic efferent activity. Unfortunately, this would require a large dose of local anesthetic, which may increase the possibility of hypotension. Second, because of the unpredictable spread and slower onset of epidural blockade, ${ }^{8)}$ epidural anesthetics are administered incrementally until the desired level of sensory analgesia is achieved, which can be quite time consuming. Finally, it is not clear whether epidural anesthesia can completely block sympathetic efferent activity ${ }^{9,10)}$ and thus completely suppress hemodynamic responses to a strong stimulus such as tracheal intubation. 
We sought to examine whether preoperative TEA alone can maintain stable blood pressure (BP) within the range of baseline values after tracheal intubation and whether the BP response to tracheal intubation could be completely blunted by increasing doses of $1.5 \%$ lidocaine administered preoperatively.

\section{MATERIALS AND METHODS}

After obtaining approval from the local institutional ethics committee and informed consent from the subjects, 81 patients, aged 45-75 years and ASA I-II, who were scheduled for major abdominal surgery were enrolled. Patients with contraindications to neuraxial block, those taking anti-hypertensive drugs, and those with previous back surgery, diabetes, renal failure, or severe cardiovascular or respiratory disease were excluded.

No premedication was given to patients before arrival in the operating room. On arrival, standard monitoring, including electrocardiography, pulse oximetry, and automated noninvablood pressure monitoring, was started. After stabilization (10 min), baseline BP and heart rate (HR) were recorded. Lactated Ringer's solution was infused at a rate of $10 \mathrm{ml} / \mathrm{kg} / \mathrm{h}$ during the study. TEA was performed with patients lying in the left lateral decubitus position.

Depending on the operative site, the insertion level was the T7-10 intervertebral space. After skin preparation and local anesthesia, a 17-gauge Tuohy needle was inserted in a paramedian approach, with the loss of resistance to saline technique (not more than $2 \mathrm{ml}$ of saline). After negative aspiration of cerebrospinal fluid or blood, a 19-gauge, single end-hole epidural catheter (Portex, Keene, NH, USA) was inserted through the Tuohy needle in the cephalad direction, $5 \mathrm{~cm}$ into the epidural space. Following negative aspiration, $3 \mathrm{ml}$ of $1.5 \%$ lidocaine containing $15 \mu \mathrm{g}$ epinephrine were injected through the catheter as a test dose.

After $3 \mathrm{~min}$, if there was no evidence of inadvertent intravascular or intrathecal injection, patients were randomized by a computer program and allocated from a sealed envelope to receive one of three epidural solutions of $1.5 \%$ lidocaine: 0.1 $\mathrm{ml} / \mathrm{kg}(\mathrm{L} 0.1, \mathrm{n}=27), 0.2 \mathrm{ml} / \mathrm{kg}(\mathrm{L} 0.2, \mathrm{n}=27)$, or $0.3 \mathrm{ml} / \mathrm{kg}$ $(\mathrm{L} 0.3, \mathrm{n}=27)$. The epidural solution was administered by hand through the epidural catheter at a rate of $1 \mathrm{ml} / 5 \mathrm{~s}$. The BP and HR were recorded every 5 min until 15 min after injection.

Sensory analgesia was defined as insensitivity to a sharp pinprick test and was assessed in both the cephalad and cau- dad directions, bilaterally, in the midclavicular line, $15 \mathrm{~min}$ postinjection. The most cephalad and caudal dermatomes blocked on each side were determined as the analgesic segment. During this period, hypotension was diagnosed if the systolic BP (SBP) decreased by $>30 \%$ from baseline or was < $90 \mathrm{mmHg}$. Bradycardia was defined as a decrease in HR to $<45$ beats/min. For patients with preoperative SBP $<100$ $\mathrm{mmHg}$ and $\mathrm{HR}<50$ beats/min, the critical values were $10 \%$ less than the preoperative values. Values of $80 \mathrm{mmHg}$ and 40 beats/min, independent of the preoperative values, were considered to indicate hypotension and bradycardia, respectively, necessitating treatment with intravenous $5 \mathrm{mg}$ ephedrine. ${ }^{11)}$

General anesthesia was induced with intravenous sodium pentothal $(5 \mathrm{mg} / \mathrm{kg})$ and, after loss of consciousness and the eyelash reflex, intravenous rocuronium bromide $(0.9 \mathrm{mg} / \mathrm{kg})$. While maintaining the end-tidal $\mathrm{CO}_{2}$ level at $35-40 \mathrm{mmHg}$ using $100 \%$ oxygen, tracheal intubation was performed $90 \mathrm{~s}$ after the rocuronium injection. If the first attempt failed, the patient was excluded from the study. The BP and HR were recorded after induction of anesthesia, immediately after tracheal intubation, and every minute for $3 \mathrm{~min}$. The maximum values during $3 \mathrm{~min}$ after tracheal intubation were also recorded. TEA was performed by a staff anesthesiologist, and determination of the extent of sensory analgesia and the tracheal intubation were done by another certified anesthesiologist who was unaware of the selected local anesthetic solution.

The primary end-point was the maximum percentage increase from baseline for SBP during the $3 \mathrm{~min}$ after tracheal intubation. These values were compared with the baseline SBP values to evaluate whether TEA alone could maintain BP within the range of baseline values. In terms of complete blocking of the BP response, the maximum percentage increases in SBP were compared with those from the induction of general anesthesia. Secondary end-points were the distribution of TEA and the incidences of hypotension, bradycardia, and ephedrine use.

We considered that doubling the volume of local anesthetic, from 0.1 to $0.2 \mathrm{ml} / \mathrm{kg}$, would be clinically relevant if this were to cause a decrease of $50 \%(20 \mathrm{mmHg})$ or more in the rise of SBP from baseline after tracheal intubation. We used type I error $(\alpha)=0.05$ and type II error $(\beta)=0.2$ to detect this difference for a sample size of 27 per group. Statistical analyses were performed using Stata/SE 9.2 for Windows (StataCorp, College Station, TX, USA). Differences in demographic data among the three groups were analyzed by one-way ANOVA and the chi-squared test. Continuous data were analyzed using 
Table 1. Demographic Data

\begin{tabular}{lccc}
\hline & $\begin{array}{c}\text { L0.1 } \\
(\mathrm{n}=27)\end{array}$ & $\begin{array}{c}\text { L0.2 } \\
(\mathrm{n}=27)\end{array}$ & $\begin{array}{c}\text { L0.3 } \\
(\mathrm{n}=27)\end{array}$ \\
\hline Age (yr) & $60.1 \pm 10.4$ & $57.2 \pm 8.6$ & $60.7 \pm 8.9$ \\
Sex (M/F) & $16 / 11$ & $17 / 10$ & $19 / 8$ \\
Weight (kg) & $58.8 \pm 10.5$ & $61.0 \pm 8.6$ & $61.3 \pm 9.4$ \\
Height (cm) & $160.8 \pm 9.3$ & $160.8 \pm 7.9$ & $161.6 \pm 7.9$ \\
BMI (kg/m $\left.{ }^{2}\right)$ & $22.7 \pm 3.3$ & $23.5 \pm 2.8$ & $23.4 \pm 3.2$ \\
ASA physical statu (I/II) & $16 / 11$ & $12 / 15$ & $15 / 12$ \\
Baseline hemodynamic variables & & \\
SBP (mmHg) & $136 \pm 20$ & $138 \pm 16$ & $140 \pm 18$ \\
DBP (mmHg) & $72 \pm 8$ & $71 \pm 9$ & $75 \pm 12$ \\
MBP (mmHg) & $93 \pm 10$ & $93 \pm 10$ & $97 \pm 13$ \\
HR (beats/min) & $74 \pm 17$ & $77 \pm 15$ & $75 \pm 15$ \\
\hline
\end{tabular}

Values are mean \pm SD or number. L0.1, L0.2, and L0.3: patients given a single epidural bolus of $1.5 \%$ lidocaine $0.1,0.2$, and 0.3 $\mathrm{ml} / \mathrm{kg}$, respectively. SBP: systolic blood pressure, DBP: diastolic blood pressure, MBP: mean blood pressure, HR: heart rate.

Table 2. Characteristics of Epidural Anesthesia, Incidence of Hypotension, Bradycardia, and Use of Ephedrine from Administration of Epidural Lidocaine to Induction of General Anesthesia

\begin{tabular}{lccc}
\hline & $\begin{array}{c}\text { L0.1 } \\
(\mathrm{n}=27)\end{array}$ & $\begin{array}{c}\text { L0.2 } \\
(\mathrm{n}=27)\end{array}$ & $\begin{array}{c}\text { L0.3 } \\
(\mathrm{n}=27)\end{array}$ \\
\hline $\begin{array}{l}\text { Epidural catheter insertion } \\
\text { T7-T8 }\end{array}$ & 10 & 10 & 11 \\
T8-T9 & 9 & 7 & 7 \\
T9-T10 & 8 & 10 & 9 \\
Number of analgesic & $8.0 \pm 3.0$ & $11.1 \pm 4.0^{*}$ & $13.7 \pm 3.1^{*^{\dagger}}$ \\
dermatomes & & & \\
Sensory analgesia & 0 & 2 & $7^{*}$ \\
including T1-L2 & & & \\
Total volume of 1.5\% & $8.8 \pm 1.0$ & $15.2 \pm 1.7^{*}$ & $21.4 \pm 2.8^{*}$ \\
lidocaine including the & & & \\
test dose (ml) & & & \\
Hypotension & 1 & $7 *$ & $14^{*}$ \\
Bradycardia & 1 & 1 & 0 \\
Ephedrine & 1 & 2 & $7^{*}$ \\
\hline
\end{tabular}

Values are mean \pm SD or number. L0.1, L0.2, and L0.3: patients given a single epidural bolus of $1.5 \%$ lidocaine $0.1,0.2$, and 0.3 $\mathrm{ml} / \mathrm{kg}$, respectively. *: $\mathrm{P}<0.05$ versus $\mathrm{L} 0.1{ }^{\dagger}{ }^{\dagger}: \mathrm{P}<0.05$ versus L0.2.

one-way ANOVA with a post hoc Bonferroni test. Changes over time were evaluated using repeated measures ANOVA. Categorical variables were compared by contingency table analysis, with the chi-squared test and Fisher's exact test as appropriate, and the KruskalWallis test, followed by a post hoc Mann-Whitney $U$ test. Continuous variables are presented as

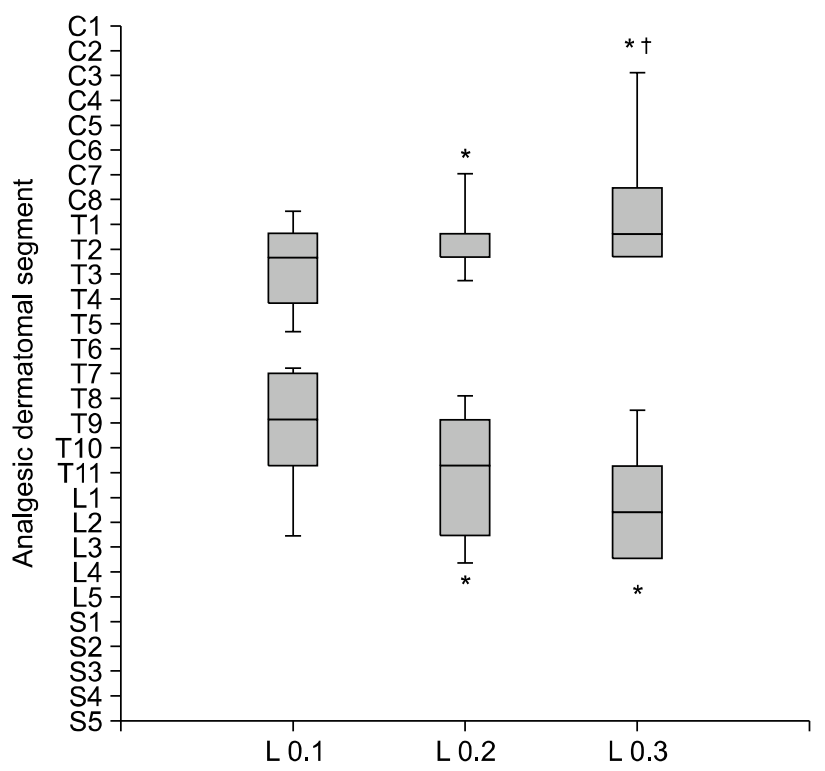

Fig. 1. This figure shows upper and lower levels of sensory block $15 \mathrm{~min}$ after epidural injection of $1.5 \%$ lidocaine. The box represents the 25-75th percentiles, and the solid lines in the boxes are the medians. Error bars above and below the box mark the 10th and 90th percentiles, respectively. L0.1, L0.2, and L0.3: patients given a single epidural bolus of $0.1,0.2$, and $0.3 \mathrm{ml} / \mathrm{kg} 1.5 \%$ lidocaine, respectively. *: $\mathrm{P}<0.05$ versus $\mathrm{L} 0.1,{ }^{\dagger}$ : $\mathrm{P}<0.05$ versus $\mathrm{L} 0.2$.

the mean \pm SD or $95 \%$ confidence interval $(\mathrm{CI})$. The $\mathrm{P}$ values $<0.05$ were considered statistically significant.

\section{RESULTS}

None of the 81 patients failed TEA or tracheal intubation. There were no significant differences in the demographic data or baseline hemodynamic variables among the three groups (Table 1).

The total number of sensory analgesic dermatomes $15 \mathrm{~min}$ after the injection of $1.5 \%$ lidocaine was significantly increased at larger doses, and the number of patients with sensory analgesia, including T1 L2, was significantly higher in L0.3 than in L0.1 (Table 2). The median values of the distribution of sensory analgesia in L0.1, L0.2, and L0.3 were T3-T10, T3T12, and T2-L2, respectively (Fig. 1).

The BP and HR were significantly decreased from injection of lidocaine to induction of general anesthesia in all groups, versus baseline (Fig. 2, 3). The SBP in L0.3 was significantly lower than that in L0.1 at 10 and $15 \mathrm{~min}$ after epidural lidocaine, and the SBP became significantly lower in L0.2 and L0.3 compared with L0.1 after induction of general anesthesia. 


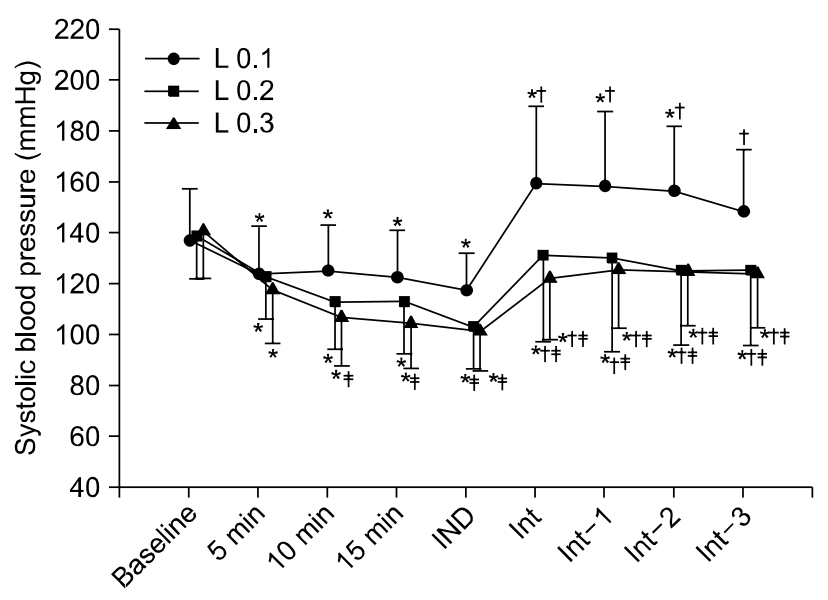

Fig. 2. This figure shows changes in systolic blood pressure from baseline to $3 \mathrm{~min}$ after tracheal intubation. Values are mean $\pm \mathrm{SD}$. L0.1, L0.2, and L0.3: patients given a single epidural bolus of $0.1,0.2$, and $0.3 \mathrm{ml} / \mathrm{kg} 1.5 \%$ lidocaine, respectively. IND: immediately after induction of general anesthesia, Int: immediately after tracheal intubation, Int-1, 2, and 3 indicate 1, 2, and 3 min after tracheal intubation, respectively. ${ }^{*}: \mathrm{P}<0.05$ versus baseline, ${ }^{\dagger}: \mathrm{P}<$ 0.05 versus induction, ${ }^{\ddagger}: \mathrm{P}<0.05$ versus $\mathrm{L} 0.1$.

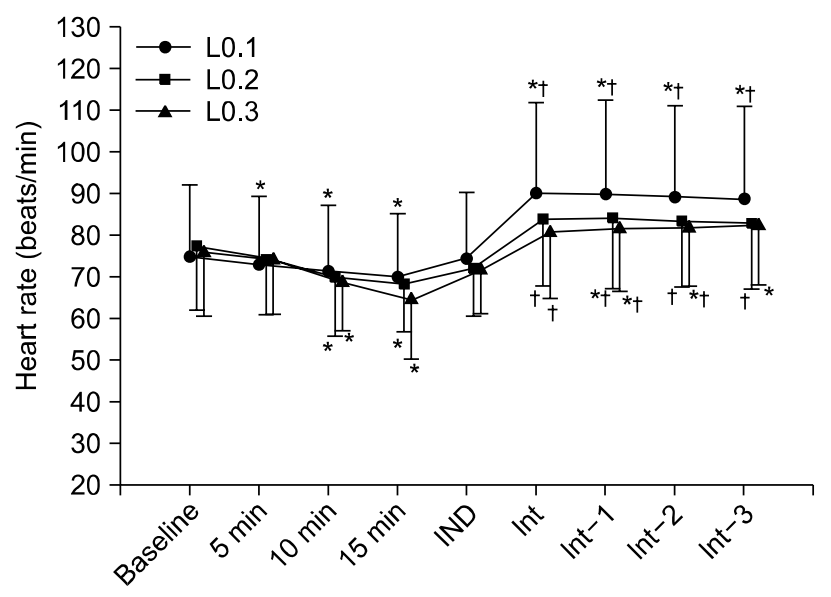

Fig. 3. This figure shows changes in heart rate from baseline to 3 min after tracheal intubation. Values are mean \pm SD. L0.1, L0.2, and L0.3: patients given a single epidural bolus of $0.1,0.2$, and $0.3 \mathrm{ml} / \mathrm{kg} 1.5 \%$ lidocaine, respectively. IND: immediately after induction of general anesthesia, Int: immediately after tracheal intubation, Int-1, 2, and 3 indicate 1,2 , and $3 \mathrm{~min}$ after tracheal intubation, respectively. ${ }^{*}: \mathrm{P}<0.05$ versus baseline, ${ }^{\dagger}: \mathrm{P}<0.05$ versus induction.

There was no statistically significant difference in HR among the three groups during this period. The numbers of patients who developed hypotension were 1,7 , and 14 in L0.1, L0.2,
Table 3. Maximum Increases in SBP, DBP, MBP, and HR from Baseline during $3 \mathrm{~min}$ after Tracheal Intubation

\begin{tabular}{llcc}
\hline & L0.1 (n = 27) & L0.2 (n=27) & L0.3 (n = 27) \\
\hline SBP (mmHg) & $27(14-41)^{*} \dagger^{\dagger}$ & $-1(-16-12)$ & $-11(-21--1)^{*}$ \\
DBP (mmHg) & $25(17-33)^{*}$ & $7(-1-15)$ & $1(-5-7)$ \\
MBP (mmHg) & $25(16-35)^{*}$ & $3(-6-13)$ & $-3(-10-3)$ \\
HR (beats/min) & $19(9-28)^{*}$ & $9(2-15)^{*}$ & $8(0-15)^{*}$ \\
\hline
\end{tabular}

Values are mean $(95 \% \mathrm{CI})$. L0.1, L0.2, and L0.3: patients given a single epidural bolus of $1.5 \%$ lidocaine $0.1,0.2$, and $0.3 \mathrm{ml} / \mathrm{kg}$, respectively. SBP: systolic blood pressure, DBP: diastolic blood pressure, MBP: mean blood pressure, HR: heart rate. ${ }^{*}: \mathrm{P}<0.05$ from baseline, ${ }^{\dagger}: \mathrm{P}<0.05$ versus $\mathrm{L} 0.2$ and $\mathrm{L} 0.3$.

and L0.3, respectively $(\mathrm{P}<0.05)$. Seven patients in L0.3 received intravenous ephedrine to treat hypotension, whereas only two in L0.2 and one in L0.1 required ephedrine $(\mathrm{P}<0.05)$. The incidence of bradycardia did not differ among the three groups (Table 2).

After tracheal intubation, the SBP significantly increased from that at induction of anesthesia in all groups. When compared with baseline SBP values, the SBP after tracheal intubation was significantly higher than baseline only in L0.1. The HR was significantly increased after tracheal intubation in all groups as compared with the baseline and induction values, but there were no significant differences in HR among the three groups (Fig. 2, 3).

The maximum increase in SBP from baseline was significantly higher in L0.1 compared with L0.2 and L0.3 (22.6\%; 95\% CI, $12.2-33.0 \%$; $-0.5 \%$; $95 \% \mathrm{CI},-11.1-10.0 \%$; and $-6.9 \%$; $95 \%$ CI, $-13.9-0.0 \%$, respectively). Actual increases in BPs and HR from baseline are described in Table 3. The maximum increase in SBP from the induction value was not significantly different among the three groups (L0.1: 41.2\%; 95\% CI, 31.451.0\%; L0.2: $31.7 \%$; 95\% CI, $23.3-40.0 \%$; and L0.3: $28.6 \%$; 95\% CI, 21.0-36.2\%).

The maximum percentage increase in HR compared with baseline was not significantly different among the three groups (30.7\%; 95\% CI, $14.9-46.5 \%$; $12.6 \%$; 95\% CI, $4.7-22.5 \%$; and $14.4 \%$; $95 \% \mathrm{CI}, 3.525 .0 \%$ in L0.1, L0.2, and L0.3, respectively). Furthermore, there was no significant difference in the maximum percentage increase in HR compared with the induction value among the three groups $(27.6 \%$; $95 \%$ CI, $18.5-$ $36.8 \%$; 20.7\%; 95\% CI, 12.6-28.7\%; and $17.8 \%$; $95 \% \mathrm{CI}$, $12.1-23.5 \%$ in L0.1, L0.2, and L0.3 respectively). 


\section{DISCUSSION}

We found that TEA with $1.5 \%$ lidocaine administered at 0.2 $\mathrm{ml} / \mathrm{kg}$ markedly blunted the BP response to tracheal intubation and resulted in a stable BP during the 3 min after tracheal intubation. However, the use of $1.5 \%$ lidocaine alone could not completely blunt the $\mathrm{BP}$ response, even at larger doses $(0.3$ $\mathrm{ml} / \mathrm{kg}$ ); maximum increases in the SBP were almost $30 \%$, compared with the SBP values at induction.

Hypertension and tachycardia during laryngoscopy and tracheal intubation are known to occur due to an increased sympathetic response caused by tracheal stimulation with the endotracheal tube. ${ }^{12)}$ Although transient hypertension and tachycardia present low risks to healthy individuals, they may be hazardous to patients with coronary artery disease, because of the detrimental effects of sympathetic hyperactivity. ${ }^{13)}$

There are many pharmacological strategies for blunting hemodynamic responses to tracheal intubation. However, because TEA is almost routinely performed in our hospital to control postoperative pain from major abdominal surgery, we sought to evaluate whether the current utility of TEA could be extended to the preoperative period by using it to blunt hemodynamic responses to tracheal intubation.

Preoperative TEA can provide hemodynamic benefits by inhibiting cardiovascular responses during tracheal intubation, through the inhibition of sympathetic activity. The sympathetic efferent nerves to the heart arise from $\mathrm{T} 1$ to $\mathrm{T} 5$; those to the vascular bed, from $\mathrm{T} 1$ to $\mathrm{L} 2$; and those to the adrenal glands, from T6 to L2. Thus, extending sensory analgesia from T1 to L2 may completely inhibit sympathetic activity during tracheal intubation. $^{5)}$

To achieve this range of sensory blockade, a relatively large dose of local anesthetic is required, which raises a concern regarding the development of hypotension. Hypotension results from the blockade of the preganglionic sympathetic nerve fibers, producing vasodilation and decreased venous return. Further, decreases in venous return along with high segmental blocking, including blockade of the upper four thoracic sympathetic segments, can cause bradycardia. Controversy exists as to whether epidural anesthesia produces sympathetic nerve blockade to at least the same extent as sensory blockade or exceeds that level by at least two segments. ${ }^{6,7)}$ Extensive epidural analgesia, from $\mathrm{T} 1$ to $\mathrm{T} 12$ or involving the upper lumbar segments, is known to interfere with nearly all sympathetic outflow and produce significant hypotension, at least partly because of its roles in cardiodepressant activity, splanchnic venous congestion, and reduction of systemic vascular resistance. ${ }^{11,14)}$ The higher incidence of hypotension in L0.3 compared with L0.2 is likely attributable to a more extensive sensory blockade involving the lumbar segments in L0.3. Nevertheless, hypotension was easily corrected in all patients by intravenous injection of ephedrine.

The main factor controlling the HR is the balance between the sympathetic and parasympathetic nervous systems, with the latter predominating. High TEA effecting the cardiac segments is known to produce small but significant reductions in the HR by sympathetic blockade and concomitant vagal predominance in controlling the $\mathrm{HR}^{14)}$ as observed in our study. Further, changes in the HR after tracheal intubation were not attenuated by increasing the dose of lidocaine. This may indicate an incomplete sympathetic blockade during epidural anesthesia (i.e., the decreased sympathetic cardio-accelerator function in the resting individual could not be maintained when exposed to the stress of tracheal intubation). ${ }^{15)}$

Previous studies have demonstrated that TEA markedly or even completely inhibits the hemodynamic response to tracheal intubation. $^{3-5)}$ Licker et al. ${ }^{3)}$ reported that TEA ranging from $\mathrm{T} 2$ to $\mathrm{L} 2$, produced by incremental administration of plain $1 \%$ lidocaine (total volume, $12.4 \pm 2.3 \mathrm{ml}$ ), markedly blunted the hemodynamic response to intubation, although some response was still present. Nakatani et al. ${ }^{4)}$ showed that TEA decreased the hemodynamic responses to laryngoscopy and tracheal intubation after a single injection of $1.5 \%$ lidocaine $(0.2 \mathrm{ml} / \mathrm{kg}$, $11 \mathrm{ml}$ ). At first glance, the results of those two studies look similar to ours in that TEA could modestly, but not completely, blunt hemodynamic responses. However, those two studies $^{3,4)}$ also administered intravenous fentanyl $(1-2 \mu \mathrm{g} / \mathrm{kg})$, which is known to decrease the blood pressure increase, at 57 min prior to tracheal intubation. ${ }^{16)}$ Thus, those previous studies $^{3,4)}$ revealed combined hemodynamic effect of TEA and fentanyl rather than TEA alone on tracheal intubation. Our study demonstrated that epidural analgesia with low-concentration lidocaine caused partial sympathetic blockade and thereby moderately decreased blood pressure responses during tracheal intubation.

An incomplete sympathetic blockade during epidural anesthesia is generally attributed to preganglionic sympathetic fibers being more resistant to local anesthetic and to insufficient local anesthetic reaching intraspinally to block the bulbospinal path- 
ways that mediate the central sympathoexcitatory drive, which is necessary for peripheral sympathetic fiber activity. ${ }^{17)}$ In contrast, Wattwil et al. ${ }^{5)}$ showed that increased blood pressure during laryngoscopy and tracheal intubation was completely inhibited through complete sympathetic blockade with sensory analgesia ranging from $\mathrm{T} 1$ to $\mathrm{L} 2$. The reason for this greater effect on blood pressure may be a more potent neural blockade caused by a high concentration of mepivacaine and its combination with epinephrine. Although the addition of epinephrine did not influence sympathetic blockade, ${ }^{18)}$ further study is required to establish whether a combination of highconcentration local anesthetic and epinephrine can completely block sympathetic activation during tracheal intubation.

Intravenous lidocaine is known to attenuate the hemodynamic response to laryngoscopy and tracheal intubation, ${ }^{19)}$ and thus it may be argued that the attenuation of the BP response in the current study is the result of a systemic effect of lidocaine. However, there is little evidence that intravenous lidocaine at $1.5 \mathrm{mg} / \mathrm{kg}$ provides protection against the tachycardic or hypertensive response to laryngoscopy and tracheal intubation. $^{20,21)}$ Furthermore, the systemic effects produced by concentrations of local anesthetics in blood that are associated with correctly performed epidural block are known to be of little clinical significance. ${ }^{14)}$ Previous reports ${ }^{2,22,23)}$ have shown that the plasma concentration of lidocaine after thoracic epidural injection of lidocaine (90 to $300 \mathrm{mg}$ ) ranged from 2.0 to $2.3 \mu \mathrm{g} / \mathrm{ml}$; this is comparable to the levels after an intravenous bolus of $1.0 \mathrm{mg} / \mathrm{kg}$ lidocaine, followed by subsequent infusion $(25 \mu \mathrm{g} / \mathrm{kg} / \mathrm{min})$. Thus, it seems unlikely that the attenuated BP response to tracheal intubation in the current study resulted from a systemic effect of epidural lidocaine.

This study has several limitations. First, the dose of epidural local anesthetic was based on body weight, which neither influences the spread of epidural anesthesia nor requires more local anesthetic to block one spinal segment. ${ }^{24,25)}$ On the contrary, as body weight increases, the amount of local anesthetic required to block one spinal segment decreases. ${ }^{26)}$ Thus, it is inappropriate to increase the local anesthetic dose according to body weight in clinical practice. Second, we did not continuously measure the hemodynamic variables. During the $3 \mathrm{~min}$ period after tracheal intubation, non-invasive blood pressure monitoring did not necessarily record the highest BP values.

In conclusion, it may be appropriate to administer a single dose of $1.5 \%$ lidocaine at $0.2 \mathrm{ml} / \mathrm{kg}$ when using TEA alone for the purpose of blunting the BP response during tracheal in- tubation with a laryngoscope, because this dose maintained the BP range within $10 \%$ of the baseline BP. However, as increasing the dose to $0.3 \mathrm{ml} / \mathrm{kg}$ produced hypotension in almost half of the patients, half of whom needed intravenous ephedrine to restore the $\mathrm{BP}$, the use $0.3 \mathrm{ml} / \mathrm{kg}$ of $1.5 \%$ lidocaine it is not recommended for this purpose.

\section{REFERENCES}

1. Block BM, Liu SS, Rowlingson AJ, Cowan AR, Cowan JA Jr, Wu CL: Efficacy of postoperative epidural analgesia: a metaanalysis. JAMA 2003; 290: 2455-63.

2. Hodgson PS, Liu SS: Epidural lidocaine decreases sevoflurane requirement for adequate depth of anesthesia as measured by the Bispectral Index monitor. Anesthesiology 2001; 94: 799-803.

3. Licker M, Farinelli C, Klopfenstein CE: Cardiovascular reflexes during anesthesia induction and tracheal intubation in elderly patients: The influence of thoracic epidural anesthesia. J Clin Anesth 1995; 7: 281-7.

4. Nakatani T, Saito Y, Sakura S, Kanata K: Haemodynamic effects of thoracic epidural anaesthesia during induction of anaesthesia: An investigation into the effects of tracheal intubation during target-controlled infusion of propofol. Anaesthesia 2005; 60: 530-4.

5. Wattwil M, Sundberg A, Olsson J, Nordstrom S: Thoracolumbar epidural anaesthesia blocks the circulatory response to laryngoscopy and intubation. Acta Anaesthesiol Scand 1987; 31: 529-31.

6. Brull SJ, Greene NM: Zones of differential sensory block during extradural anaesthesia. Br J Anaesth 1991; 66: 651-5.

7. Magnusdottir H, Kirno K, Ricksten SE, Elam M: High thoracic epidural anesthesia does not inhibit sympathetic nerve activity in the lower extremities. Anesthesiology 1999; 91: 1299-304.

8. Erdemir HA, Soper LE, Sweet RB: Studies of factors affecting peridural anesthesia. Anesth Analg 1965; 44: 400-5.

9. Peters J, Kutkuhn B, Medert HA, Schlaghecke R, Schuttler J, Arndt JO: Sympathetic blockade by epidural anesthesia attenuates the cardiovascular response to severe hypoxemia. Anesthesiology 1990; 72: 134-44.

10. Stevens RA, Artuso JD, Kao TC, Bray JG, Spitzer L, Louwsma DL: Changes in human plasma catecholamine concentrations during epidural anesthesia depend on the level of block. Anesthesiology 1991; 74: 1029-34.

11. Curatolo M, Scaramozzino P, Venuti FS, Orlando A, Zbinden AM: Factors associated with hypotension and bradycardia after epidural blockade. Anesth Analg 1996; 83: 1033-40.

12. Takahashi S, Mizutani T, Miyabe M, Toyooka H: Hemodynamic responses to tracheal intubation with laryngoscope versus lightwand intubating device (Trachlight) in adults with normal airway. Anesth Analg 2002; 95: 480-4.

13. Montes FR, Giraldo JC, Betancur LA, Rincón JD, Rincón IE, Vanegas MV, et al: Endotracheal intubation with a lightwand or a laryngoscope results in similar hemodynamic variations in pa- 
tients with coronary artery disease. Can J Anaesth 2003; 50: 824-8.

14. Veering BT, Cousins MJ: Cardiovascular and pulmonary effects of epidural anaesthesia. Anaesth Intensive Care 2000; 28: 620-35.

15. Stevens RA, Beardsley D, White JL, Kao TC, Gantt R, Holman $\mathrm{S}$ : Does spinal anesthesia result in a more complete sympathetic block than that from epidural anesthesia? Anesthesiology 1995; 82: $877-83$.

16. Ko SH, Kim DC, Han YJ, Song HS: Small-dose fentanyl: optimal time of injection for blunting the circulatory responses to tracheal intubation. Anesth Analg 1998; 86: 658-61.

17. Stjernberg L, Blumberg H, Wallin BG: Sympathetic activity in man after spinal cord injury. Outflow to muscle below the lesion. Brain 1986; 109: 695-715.

18. Cederholm I, Anskar S, Bengtsson M: Sensory, motor, and sympathetic block during epidural analgesia with $0.5 \%$ and $0.75 \%$ ropivacaine with and without epinephrine. Reg Anesth 1994; 19: 18-33.

19. Stoelting RK: Circulatory changes during direct laryngoscopy and tracheal intubation: Influence of duration of laryngoscopy with or without prior lidocaine. Anesthesiology 1977; 47: 381-4.

20. Chraemmer-Jorgensen B, Hoilund-Carlsen PF, Marving J, Christensen
V: Lack of effect of intravenous lidocaine on hemodynamic responses to rapid sequence induction of general anesthesia: A double-blind controlled clinical trial. Anesth Analg 1986; 65: 1037-41.

21. Miller $\mathrm{CD}$, Warren SJ: I.v. lignocaine fails to attenuate the cardiovascular response to laryngoscopy and tracheal intubation. $\mathrm{Br}$ J Anaesth 1990; 65: 216-9.

22. Hodgson PS, Liu SS, Gras TW: Does epidural anesthesia have general anesthetic effects?: A prospective, randomized, doubleblind, placebo-controlled trial. Anesthesiology 1999; 91: 1687- 92.

23. Yokoyama M, Mizobuchi S, Nagano O, Fujii H, Yamashita M, Hirakawa M: The effects of epidural insertion site and surgical procedure on plasma lidocaine concentration. Anesth Analg 2001; 92: $470-5$

24. Duggan J, Bowler GMR, McClure JH, Wildsmith JAW: Extradural block with bupivacaine: Influence of dose, volume, concentration and patient characteristics. Br J Anaesth 1988; 61: 324-31.

25. Grundy EM, Ramamurthy S, Patel KP: Extradural analgesia revisited. A statistical study. Br J Anaesth 1978; 50: 805-9.

26. Curatolo M, Orlando A, Zbinden AM, Scaramozzino P, Venuti FS: A multifactorial analysis of the spread of epidural analgesia. Acta Anaesthesiol Scand 1994; 38: 646-52. 